\title{
A PRÁTICA PEDAGÓGICA PARA A DIVERSIDADE CULTURAL NA ESCOLA DO CAMPO RIBEIRINHA
}

\author{
Maria Auxiliadora dos Santos Coelho ${ }^{1}$ \\ Josenildo Santos de Souza ${ }^{2}$
}

\begin{abstract}
RESUMO
Este artigo, é parte de uma produção acadêmica científica de Conclusão de Curso, versa sobre a diversidade cultural na Escola do Campo Ribeirinha, traz como questão central o trabalho educativo do professor e sua prática pedagógica que possibilite o reconhecimento da diversidade cultural do espaço da sala de aula e potencializa a inter-relação entre os sujeitos do processo educativo. Fazemos um recorte dos resultados que objetivou analisar a metodologia do (a) professor(a) para trabalhar com a diversidade cultural na escola do campo ribeirinha. A pesquisa foi realizada no município de Benjamin Constant, Estado do Amazonas, com base na abordagem qualitativa utilizando-se de observações participantes em sala de aula e na escola, entrevistas semiestruturadas e análises de documentos, que permitiram discutir e refletir sobre o contexto educacional, as singulares e especificidades dos sujeitos no contexto escolar. A investigação apontou que apesar da existência de uma grande diversidade cultural no cotidiano da sala de aula e os parâmetros legais e didáticos que orientam o trabalho pedagógico, esta diversidade não é contemplada nas práticas docentes de sala de aula e tampouco no ambiente educacional. Diante do exposto, se impõem um grande desafio para modificar a forma como a prática efetiva, proporcionando vivências interculturais, sobretudo, nas metodologias que possam considerar os aspectos socioculturais oriundos dos educados, seus familiares e comunidade do entorno da escola. Por fim, é necessário uma maior aproximação dos conhecimentos teóricos com os conhecimentos e vivências culturais dos educandos, com vista a uma interação dialógica entre os sujeitos.
\end{abstract}

Palavras-chave: Diversidade cultural. Prática pedagógica. Escola do campo ribeirinha.

\begin{abstract}
This article is part of a scientific production of Completion of Course, versa on cultural diversity in the Ribeirinha Field School, brings as a central issue the educational work of the teacher and his pedagogical practice that allows the recognition of the cultural diversity of the space of the classroom and enhances the interrelation between the subjects of the educational process. We make a clipping of the results that aimed to analyze the methodology of the teacher to work with the cultural diversity in

\footnotetext{
${ }^{1}$ Mestranda no Programa de Pós-Graduação em Educação da Universidade Federal do Pará. Graduada em Licenciatura Plena em Pedagogia pela Universidade Federal do Amazonas - UFAM (2011). Especialização Lato Sensu em educação infantil e ensino fundamental pela Faculdade Integrada do Brasil- FAIBRA (2014). Professora do Instituto de Natureza de Natureza e Cultura - INC/UFAM no Curso de Pedagogia. Participa do Observatório da Educação do Campo no Alto Solimões (OBECAS). Tem experiência na área de Educação, atuando principalmente nos seguintes temas: Educação do campo/ ribeirinha; Diversidade cultural; Práticas pedagógicas.

${ }^{2}$ Possui graduação em Filosofia pela Universidade Federal do Amazonas UFAM (2001), especialização em Ética pela Universidade Federal do Amazonas UFAM (2002). Mestre em Estudos Amazônicos pela Universidad Nacional de Colômbia - UNAL, linha de pesquisa Desenvolvimento Regional. Professor Auxiliar IV da Universidade Federal do Amazonas, no Instituto Natureza e Cultura - Benjamin Constant - Campus Alto Solimões. Tem experiência na área de Filosofia, com ênfase em Filosofia Geral. Atuando principalmente nos seguintes temas: filosofia geral, filosofia da educação. Atualmente participa como colaborador no projeto de pesquisa Observatório da Educação do Campo no Alto Solimões - OBECAS. Participante do grupo de pesquisa Documentação visual (mundo rural e história ambiental) liderado pelo Professor Doutor Héctor Alberto Alimonda
} 
the school of the riverside field. The research was carried out in the municipality of Benjamin Constant, State of Amazonas, based on the qualitative approach using participant observations in the classroom and at school, semistructured interviews and analysis of documents, which allowed to discuss and reflect on the educational context, the singularities and specificities of the subjects in the school context. The research pointed out that despite the existence of a great cultural diversity in the daily life of the classroom and the legal and didactic parameters that guide the pedagogical work, this diversity is not contemplated in the teaching practices of the classroom nor in the educational environment. In view of the above, a great challenge is required to modify the way in which the practice is effective, providing intercultural experiences, above all, in the methodologies that can consider the socio-cultural aspects of the educated, their families and the community around the school. Finally, a closer approximation of the theoretical knowledge with the knowledge and cultural experiences of the students is necessary, with a view to a dialogical interaction between the subjects.

Keywords: Cultural diversity. Pedagogical practice. School of the riverside field.

\section{INTRODUÇÃO}

O presente artigo, é resultado de uma produção acadêmica de Conclusão de Curso de graduação, trata sobre a prática pedagógica do professor de escola ribeirinha articulando a diversidade cultural que permeia esse espaço, e que contribua para a interculturalidade no processo educativo. Tivemos como objetivo analisar a metodologia do (a) professor (a) para trabalhar com a diversidade cultural na escola do campo ribeirinha.

A pesquisa foi realizada na Escola municipal Capitão Avelino Nogueira, comunidade Santo Antônio, no município de Benjamin Constant, Estado do Amazonas, com base na abordagem qualitativa utilizando-se de observações participantes em sala de aula e na escola, entrevistas semi-estruturadas e análises de documentos, que permitiram discutir e refletir sobre o contexto educacional, as singulares e especificidades dos sujeitos no contexto escolar.

Entendemos que a sociedade é marcada por uma multiplicidade de culturas que se estabelece em uma complexa rede de interações entre sujeitos de diferentes identidades culturais. A multiplicidade de culturas que permeia os espaços formativos evidencia a necessidade em promover uma educação que visibilize a diversidade, contribuindo para a mudança do pensamento etnocêntrico.

Para que possa romper com a exclusão de grupos historicamente enquadrados em territórios de desigualdades sociais como os ribeirinhos, quilombolas, indígenas, extrativistas coletadores dos produtos da floresta, entre tantos outros que manifestam sua identidade singular, a educação deve integrar a diversidade cultural aos saberes e fazeres educacionais ao olhar crítico dos educados sobre a realidade onde a escola encontra-se inserida. 
Muito embora seja uma urgência o trabalho didático pedagógico a partir e sobre a diversidade cultural, a escola tem ignorado esta diversidade que foge aos padrões hegemônicos e colonizadores, não tem assumido de fato o compromisso com os conhecimentos construídos pelos diferentes grupos sociais e suas particularidades locais, por considerar a cultura ocidental hegemônica determinante enquanto cultura padrão, imposta a sociedade. Parece que a escola tem dificuldades em perceber e reconhecer que nos espaços educacionais existe uma diversidade cultural dos seus membros que integram diferentes culturais, posições sociais e políticas diversas, que não condiz com a concepção colonial e universal de cultura.

Nesta perspectiva, este artigo apresenta parte de Trabalho de Conclusão de Curso em Pedagogia, que busca responder a seguinte indagação: Como o professor tem contemplado a diversidade cultural na sala de aula, considerando a realidade ribeirinha e fronteiriça no Alto Solimões/AM?

Sendo um tema transversal afirmado nos Parâmetros Curriculares Nacionais e a realidade cultural da Tríplice Fronteira - Brasil, Colômbia e Peru, em particular Benjamin Constant/AM, considera-se importante e necessário discussões, estudos e pesquisa que vislumbrem promover uma educação votada para o reconhecimento desta realidade fronteiriça. Tomada como referência essa diversidade deve ser garantida nas práticas concretas da escola como norte para uma prática cidadã emancipatória.

Neste sentido é apresentado como questão central o trabalho educativo do professor e sua prática pedagógica no reconhecimento da diversidade cultural do espaço da sala de aula e a inter-relação entre os sujeitos do processo educativo.

\section{MARCOS TEÓRICO-METODOLÓGICO: BREVES REFLEXÕES}

Muito se tem falado em diversidade cultural no mundo, e no Brasil não é diferente. No campo da educação, a diversidade cultural é fomentada enquanto proposta educacional na legislação dos Parâmetros Curriculares Nacionais - Temas Transversais, mas pouco se faz para que "essa diversidade efetivamente faça parte do exercício diário da nossa vida no mundo, que tem a ver com nosso comportamento, atitudes e formas de relacionamento". (LUCIANO, 2008, 65-66).

José Barros (2008, p. 18) destaca que a Diversidade Cultural é "cultura e não natural, ou seja, resulta das trocas entre sujeitos, grupos sociais e instituições a partir de suas diferenças, mas também de suas desigualdades, tensões e conflitos". O reconhecimento da 
importância da diversidade cultural no mundo, enquanto uma urgência para a educação é por meio da Convenção da UNESCO sobre a Proteção e a Promoção a Diversidade das Expressões Culturais, na perspectiva em pensar estratégias educacionais sob o signo da diversidade cultural.

Cesária Macedo (2008 p. 98) argumenta que a cultura é uma ferramenta eficiente para universalizar o enfrentamento às desigualdades sociais e potencializar conquistas para a melhoria da qualidade de vida. Entretanto, a educação brasileira "ainda não proporciona aos usuários dos equipamentos de ensino o acesso de cada cidadão à Diversidade Cultural, à cultura universal, aquela que é singular de sua comunidade, de sua região e de seu país", porque as políticas educativas, sociais e culturais, não tem sido implementada considerando a realidade das classes populares, dos menos favorecidos, dos sujeitos que vivem e fazem cultura, deixando seus saberes, conhecimentos e experiências excluídos do processo de ensino e aprendizagem.

Vivemos num espaço em que os paradigmas dominantes de alienação, homogeneização e exclusão fazem parte da vida dos sujeitos, onde as desigualdades prevalecem nas relações sociais e educativas. Isso remete a indagar o processo de colonização ao qual fomos submetidos, onde a heterogeneidade foi marcada pela negação de todos os direitos, principalmente de ser reconhecido a partir e na diferença. Logo, é garantido isso, somente a partir de lutas, de resistências e ressignificações das diferentes culturas, como forma de contrapor o modelo dominante de pensar e definir o outro.

A diversidade cultural impõe a educação para o século XXI, a questionar o seu papel frente à realidade pluriétnica e intercultural, que promova debates, reflexões, seja no ensino básico ou ensino superior, que possa conduzir a projetos de pesquisa ou de extensão para enfrentar os desafios sociais que marcam nosso cotidiano no mundo contemporâneo.

Desse modo, a educação assume um papel importante no reconhecimento e valorização da diversidade cultural que permeia a sociedade. Por meio dela pode-se enfrentar os conflitos e exclusão a que são submetidas as pessoas, assim como desconstruir a formação monocultural estabelecida socialmente. E, descontruindo a partir da alteridade, do reconhecer o outro como capaz, como diferente, que aprende e ensina, que tem conhecimentos, sem desqualificar as diferentes manifestações de suas culturas.

Maria Regina Capelo (2003, p. 129-130) faz algumas reflexões sobre a educação enquanto um espaço heterogêneo do saber, dizendo que é necessário: 
diferentes, que se compromete com a heterogeneidade sem, no entanto, usá-la para produzir novos submetidos. Uma educação conduzida pela solidariedade, contra as desigualdades, preconceitos e discriminações, ao mesmo tempo em que garante, para além da apropriação, a produção de novos conhecimentos impressos e imagéticos menos etnocêntricos.

Neste sentido, a educação deve garantir a heterogeneidade nos seus espaços de discussão, a contar dos espaços institucionalizados como a escola. Esta, como espaço de formação intelectual dos sujeitos, deve repensar o modelo hegemônico a que é submetida, desafiando seus professores, alunos e pais a perceberem-se como diferentes e semelhantes.

Além disso, é preciso rever as questões políticas pedagógicas que ainda são fragmentadas e alienadoras, seguidas pela perspectiva monocultural, que será superada somente por uma educação intercultural, que reconheça as diferentes culturas e possibilita o diálogo entre elas.

Isso implica romper com uma cultura escolar que se encontra incorporada em nossas mentes, em nossos corpos e nas nossas práticas. Implica romper com uma memória escolar, com uma história, uma racionalidade, portanto se trata de um processo que demanda tempo e, no entanto, não pode arrastar-se indefinidamente ao longo dos anos. (CAPELO, 2003, p.131)

Considerando isso, a escola precisa se reconstruir, rever suas ideologias e formas de organizar o saber formal, pois só assim poderá dar espaço a construção da subjetividade e reconhecimento das identidades sociais que ali estão, dar visibilidade as culturas que estão suprimidas no interior deste espaço.

Logo, é necessário reconhecer que esta diversidade permeia a realidade amazônica, desde seu território, as pessoas, a fauna, a flora. Mas, a Amazônia é um extenso território de desigualdades sociais que abriga uma mega bio/sociodiversidade, que evidencia a necessidade imperiosa de uma educação para a diversidade cultural, especificamente as populações indígenas, ribeirinhas, quilombolas, extrativistas, pescadores, agricultores, seringueiros e outros que compõem o mosaico populacional.

Nessas realidades as comunidades são "caracterizadas como: culturalmente diferentes, com direitos à terra e outros direitos baseados no uso e na ocupação histórica. Suas culturas, economias e identidades estão inextricavelmente ligadas às suas terras e recursos tradicionais" (IUCN; UNEP; WWF apud LIRA; CHAVES, 2015, p. 70).

Nessa perspectiva, Capelo (2003, p. 130) diz “a educação na sociedade brasileira nunca será completa, caso desconsidere a pluralidade de saberes e valores culturais de seu próprio povo". Significa dizer que a diversidade cultural que permeia a Amazônia precisa ser 
considerada elemento fundante na educação, para romper de fato com o paradigma dominante impetrada nesse espaço.

Neste sentido, o campo de pesquisa foi a Escola Municipal Capitão Avelino Nogueira, na comunidade Santo Antônio, município de Benjamin Constant-Amazonas, em uma turma multisseriada do ensino fundamental, entende este território amazônico como um lugar que evidencia várias subjetividades, culturas, identidades que precisam ser reconhecidas e valorizadas.

Assim, a pesquisa foi baseada na abordagem qualitativa, considerando a subjetividade dos sujeitos e sua realidade sociocultural. Pautada em estudos bibliográficos que deram suporte para fundamentar e compreender o processo educacional numa escola ribeirinha foi realizado uma pesquisa de campo, na referida escola e comunidade, por um período de um ano em 2011.

$\mathrm{Na}$ pesquisa de campo pode-se investigar a temática, confrontado as concepções teóricas com a realidade, contribuindo no aprimoramento do conhecimento sobre a temática em questão. Isso baseado em Minayo (1994, p.61) que nos afirma que a pesquisa em campo "permite a aproximação do pesquisador da realidade sobre a qual formulou uma pergunta, mas também estabelecer uma interação com os 'atores' que confrontam a realidade”. Dessa forma, contribuiu no desenvolvimento deste trabalho, por facilitar o acesso a informações, vivências com os alunos e professora no contexto escolar.

Utilizou-se das técnicas de observação participante em sala de aula e na escola, entrevista semiestruturada com o professor e análises de documentos, dentre eles o diário de classe, baseados na abordagem qualitativa. Triviños (1987) aponta que no enfoque qualitativo privilegia a subjetividade dos sujeitos e seu espaço, dando possibilidade de enriquecimento da investigação de forma descritiva.

\section{A INVISIBILIDADE DA DIVERSIDADE CULTURAL NAS PRÁTICAS PEDAGÓGICAS}

Ao tratarmos da prática do professor, explícito está o planejamento, a organização do ambiente educativo, materiais didáticos, a postura do professor e sua relação com os alunos, atividades e processo avaliativo.

Sabemos que o planejamento no contexto escolar é fundamental e necessário para o desenvolvimento eficiente das práticas pedagógicas em sala de aula, assim como o ponto de referência para que tais práticas sejam excludentes ou includentes. Neste sentido, observou-se 
que os planejamentos em contexto ribeirinhos ainda são falhos, sem acompanhamento e orientação da coordenação pedagógica. Pois, este planejamento seria durante as sextas-feiras, conforme determinava a secretaria de educação, contudo durante a pesquisa foi percebido que não havia tal ação, por ser somete duas professoras na referida escola, ambas combinavam de fazer em suas casas e se retiravam da escola mais cedo.

Ainda que trouxessem de suas casas o planejamento, nota-se que este não condizia com a realidade dos educados, principalmente por ser uma turma multisseriada, multicultural, onde havia alunos indígenas ticunas e cocamas, não-indígenas, crianças com necessidades especiais, além da distorção idade-série.

Esta afirmação foi possível ao ter acesso ao diário de classe, por percebermos a elaboração de conteúdos disciplinares conforme o livro didático (que somente a professora tinha acesso, os alunos não recebiam o livro didático) que consideravam a realidade sulista do Brasil, em desacordo com a realidade de vida dos educandos.

Além disso, durante a pesquisa não foi notado atividades que contemplassem temas relacionados à diversidade cultural, vez e quando somente discursos de respeito ao próximo quando de alguma brincadeira entre as crianças. Assim, os planejamentos eram meramente um documento de formalidade de conteúdos curriculares, isto é, conteúdos que a escola impunha a ser ensinada para aquela faixa etária e turma, e ainda como documento comprobatório de trabalho para a secretaria de educação.

Desse modo, consideramos necessário que temáticas que envolvam a diversidade cultural estejam articuladas expressamente no planejamento do professor, como uma forma de incentivar as crianças o reconhecimento e o respeito ao que é diferente, como afirma Macedo (2005, p.15) diz que "[...] o respeito é um dos caminhos para se aprender a conviver com as diferenças e, quem sabe, preparar para uma inclusão no sentido verdadeiro do termo", considerando que essas comunidades são orientadas por valores socioculturais na dinâmica da realidade amazônica.

Outro elemento importante nesta discussão foi a organização do ambiente educativo. Neste, foi percebido um espaço urbano em um contexto ribeirinho, a estrutura escolar toda em alvenaria sem espaços para as atividades escolares, pois havia somente duas salas de aula, uma mini-secretaria (onde funcionava a sala da coordenação e a biblioteca), a cozinha, e um pequeno pátio (figura 1). 
Figura 1. Escola Municipal Capitão Avelino

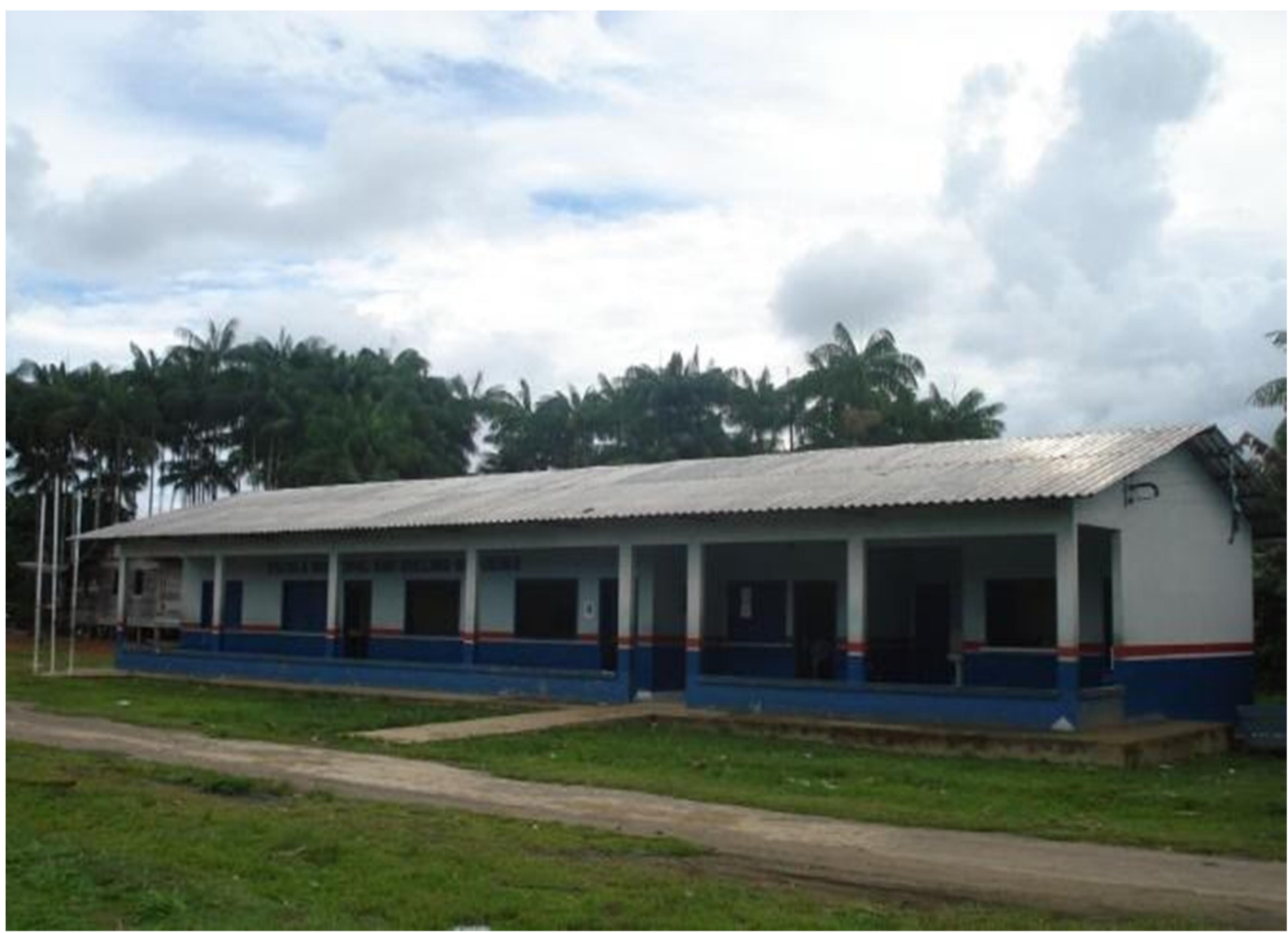

Fonte: Acervo da pesquisadora.

Esse espaço era pensado e construído de acordo com os padrões de escola urbana, incluindo pinturas e a arquitetura, desconsiderando as questões culturais e sociais da referida comunidade escolar, onde vivem e convivem alunos de diferentes grupos étnicos e religiosos. Isto é, uma escola "emparedada" numa concepção homogênea, em que o modelo precarizado de estrutura física e didática visam atender as exigências do sistema excludente e limitado. Porém, precisa ser um espaço de transformação, de diálogo, de reconhecimento e valorização dos sujeitos que dela fazem parte.

Nessa perspectiva, Cristo-Leite (2017, p.185) alega que "a escola é, sem dúvida, uma instituição cultural". Assim, afirmamos que a cultura e a diversidade dos sujeitos estão entrelaçados no ambiente escolar, ou deveriam estar, para que seja um espaço de construção coletiva de conhecimentos, em que os saberes e fazeres sejam o fio condutor do processo de ensino-aprendizagem.

Cabe dizer, portanto, da necessidade de espaços para os professores produzirem seus materiais e ambientes de convivência, ainda que tenha um espaço natural amplo, é importante que as instituições escolares deem condições de trabalho e aprendizagem. 
A sala de aula pouco atrativa, apenas cartazes diversos, confeccionados para trabalhar leitura e reconhecimento de palavras e números, não explorado pelo educador. Além dos materiais serem pouco ou quase nada, não tinha relação com a realidade que vivenciavam os educandos. Um fator a destacar era a falta de ventilação e iluminação que também afetava o processo de aprendizagem.

Nunes (2006, p.156) enfatiza que “[...] a exploração didático pedagógica do espaço é o encontro com as pessoas do lugar, com as suas casas, com uma realidade concreta que pode estar sendo revista com um olhar que não é normatizador, mas problematizador". Entretanto, muitos educadores enfrentam dificuldades em promover uma educação problematizadora, tendo em vista a falta de bibliotecas, a formação adequada dos educadores, ausência de livros didáticas apropriado a realidade do educando, são fatores que influenciam na realidade educativa.

O ambiente da sala de aula deve ser o lugar do educando, em que se perceba parte, onde reconheça sua vida, seus modos de ser e viver para assim, contribuir na construção de conhecimentos. Esse espaço deve, portanto, ser organizado e arquitetado de acordo com a realidade social, pois o contexto social e educativo permite dialogar com o processo de ensino-aprendizagem.

Essas populações desenvolvem intensa relação com o rio, a pesca, o manejo dos recursos naturais na exploração do artesanato, coleta dos produtos da floresta, no plantio da agricultura familiar, seja no período da subida do rio ou na vazante em um constante processo dialógico de produção coletiva do conhecimento.

Porém, a sala em pesquisa, tinha a organização em filas (figura 2), no modelo tradicional escolar, em que as crianças são colocadas umas atrás das outras, sem contato no olhar, preparados para o ensino também tradicional, alienado e dependente, impedindo a relação dialógica entres eles. 
Figura 2. Organização enfileirada da sala de aula

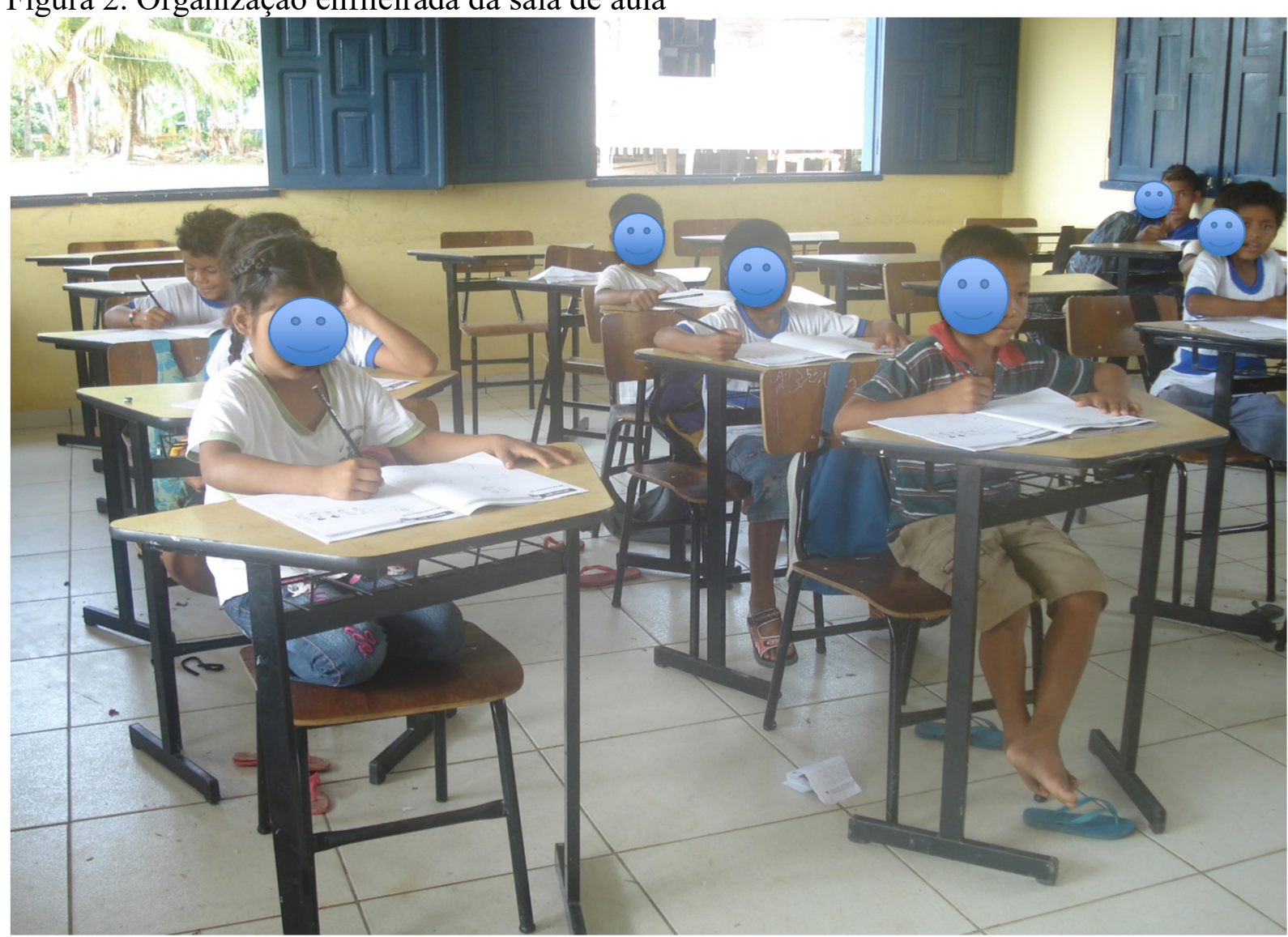

Fonte: Acervo da pesquisadora.

Nesta perspectiva, Piletti (1985) ressalta que:

O tipo de sala de aula, a disposição das carteiras e a posição dos alunos, por exemplo, são aspectos importantes. Uma sala de aula mal iluminada e sem ventilação em que os alunos permanecem sempre sentados na mesma posição, cada um olhando as costas do que está na frente, certamente é um ambiente que pode favorecer a submissão, a passividade e a dependência, mas não o trabalho livre e criativo (PILETTI, 1985, p.149).

Esses fatores implicam diretamente na prática pedagógica do professor, que acabava sendo centralizada numa concepção tradicional, em que prevalecia a transmissão de conteúdos disciplinares de língua portuguesa, matemática, geografia e história, dissociadas da realidade da comunidade. O método utilizado era quase sempre cópias do quadro negro (figura 3), já que as crianças não tinham livro didático ou outro material a ser utilizado. Inclusive, destaca-se que a escola havia participado do Programa Escola Ativa ${ }^{3}$, e adquiriu materiais didáticos que ficava salvaguardado na coordenação, sem utilização pelos alunos.

\footnotetext{
${ }^{3}$ O Programa Escola Ativa (PEA), busca melhorar a qualidade do desempenho escolar em classes multisseriadas das escolas do campo. Entre as principais estratégias estão: implantar nas escolas recursos pedagógicos que estimulem a construção do conhecimento do aluno e capacitar professores. O programa inicia em 2007 no
} 
Figura 3. Atividade no quadro

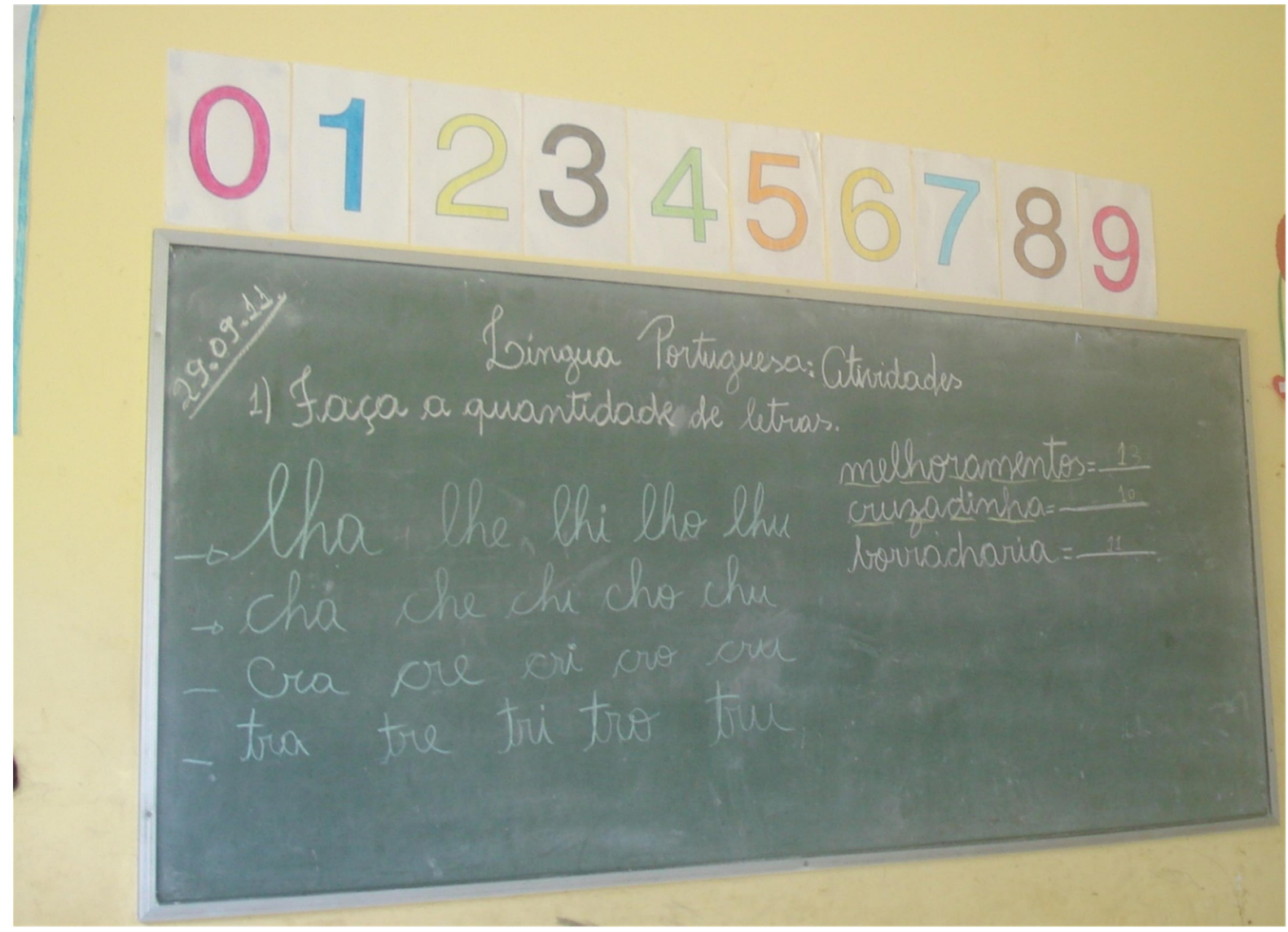

Fonte: Acervo da pesquisadora.

A prática pedagógica desenvolvida em sala de aula preocupava-se tão somente com alcance de conteúdos curriculares, em que a cultura urbana, da classe dominante requer para manter os alunos alienados, sem formação política, social, desconsiderando sua cultura e modos de produzir e construir conhecimentos.

Durante as observações, conversas informais e entrevistas o professor afirma a dificuldade em trabalhar nos contextos rurais, devido à falta de ajuda e condições de trabalho, bem como formação continuada para trabalhar com diversidade que permeia a sala de aula. $\mathrm{O}$ autor Araújo (2004) afirma:

A educação nas áreas rurais deve ser planejada de acordo com as necessidades do rurícola, estabelecendo como conditio sine qua non uma crítica radical de seus fundamentos sociais e de suas condições de existências, buscando, através dessa crítica, o pleno desenvolvimento de um saber litigante, necessário ao exercício do direito à cidadania do homem rural (ARAÚJO, 2004, p.27).

âmbito da Coordenação Geral de Educação do Campo- CGEC/SECAD/ MEC, voltado aos educadores que atuam em escolas com classes multisseriadas nos anos iniciais do ensino básico. (BRASIL, MEC, 2010) 
Acredita-se que é preciso tornar a aula mais dinâmica, de forma interdisciplinar, articulando diferentes disciplinas, trazendo a diversidade para as discussões no contexto da sala de aula e sua articulação a realidade sociocultural da comunidade. Assim sendo, possibilitaria o enriquecimento dos conhecimentos dos educandos, contribuindo com o desenvolvimento de suas habilidades cognitivas, éticas, afetivas e sociais.

Macedo (2005) destaca:

[...] por mais que defendamos teoricamente a inclusão de todas as crianças na escola, na prática ainda somos dominados por um modo de pensar, por um cotidiano e por uma organização escolar que ainda não "esqueceu", que ainda tem "saudades" da cultura anterior. Nesta cultura, as crianças que entram e permanecem na escola devem se submeter a tarefas e recursos de ensino comum (MACEDO, 2005, p.11).

Todavia, na educação ainda prevalece esta situação, em que o discurso de inovação metodológica, de formação é necessário, contudo, o que se observa em sala de aula é a afirmação de práticas pedagógicas excludentes, despreocupadas com o ser humano, com o sujeito que também ensina, pela bagagem cultural que carrega, pois acabamos construindo a mesma prática tradicional tanto criticada no interior da escola.

Candau (2014, p. 32) afirma que é necessário uma prática intercultural que reconheça as diferenças, trabalhando na perspectiva de emancipação social. Desse modo,

[...] é importante que as práticas educativas partam do reconhecimento das diferenças presentes na escola e na sala de aula, o que exige romper com os processos de homogeneização, que invisibilizam e ocultam as diferenças, reforçando o caráter monocultural das culturas escolares.

Ainda foi percebido na pesquisa, a falta de atividades e materiais relacionados à realidade dos educandos, principalmente de recursos didáticos para a diversidade cultural que favoreça a prática pedagógica do professor na escola. Consideramos que isso implica diretamente na formação dos educandos, pois a utilização de materiais que apresenta a realidade social e cultural das crianças, permite a elas se perceberem como parte do processo educativo. Além de ser uma forma didática de facilitar a aprendizagem, por meio da interação dos saberes culturais e os saberes escolares.

Caso contrário será mais uma forma de inferiorizar os sujeitos que vivem nos espaços rurais, mostrando a prevalência da visão hegemônica que afirma o status quo nesses espaços da ruralidade. Além de que a ausência desses materiais impossibilita um trabalho didático mais dinâmico e envolvente para as crianças que trazem consigo uma bagagem cultural, social e intelectual riquíssima apreendida a partir de sua relação com as suas vivências com as águas, as florestas, as terras firmes e alagadas. Logo, é urgente que se reflita no âmbito 
escolar um currículo e prática articulando os saberes e as vivências aliada ao conhecimento cultural por eles produzidos e que dê sentido ao ensino na sala de aula. Pois, "isto implica em uma educação com perspectivas emancipatórias, que objetive a construção de uma sociedade mais democrática, mais participativa" (CRISTO-LEITE, 2017, p.185).

No que se refere à avaliação como elemento importante da prática, percebeu-se que é utilizado como instrumento de regulação, assim como o sistema de ensino impõe. As crianças fazem atividades avaliativas objetivas e subjetivas repassadas pela professora, com perguntas retiradas do livro didático ou cópias do quadro negro. Sem finalidade de uma formação crítica, mas como uma forma de treinar os alunos a decorarem determinados conteúdos. É preciso, portanto, que o professor reveja o processo avaliativo considerando o lugar, os sujeitos e seu processo de aprendizagem, suas histórias de vida, como propõe Freire (2003), que a prática educativa deve ultrapassar ao tecnicismo, ao treinamento de destrezas, mas uma prática de liberdade.

Portanto, envolver a educação, com a diversidade social e cultural, ambiental, territorial e econômica na comunidade de Santo Antônio, é permitir a possibilidade para criar as condições que favoreçam a melhoria da qualidade de vida dessas populações, historicamente a margem de uma educação de qualidade, laica e socialmente referenciada.

\section{CONSIDERAÇÕES FINAIS}

A prática pedagógica de escolas ribeirinhas é o marco no trabalho educativo com crianças, que tem uma bagagem cultural imersa nos saberes das águas, das terras e da floresta. Esses saberes culturais devem, portanto, ser garantidos no âmbito escolar, como possibilidades e alternativas de aprender e ensinar com os sujeitos.

Contudo, o que se pode perceber é que ainda é um desafio considerar a riqueza da diversidade cultural na sala de aula, apesar de estar visível a diversidade étnica, religiosa, social que as crianças apresentam. Tal desafio perpassa pela estrutura física da escola, pelo currículo escolar, mas principalmente pelas práticas cotidianas que compreendem tão somente conteúdos disciplinares de português, matemática, ciências, desconsiderando a aprendizagem territorial que esses sujeitos têm apreendido.

$\mathrm{Na}$ escola em questão é marcada por um processo homogeneizador do conhecimento, que nega os direitos das crianças de aprenderem a partir de sua realidade, conforme determinada a LDBEN no artigo 28. Processo este que invisibiliza a diversidade sociocultural que há neste ambiente educativo, consolidando um sistema de alienação e exclusão. 
Diante disso, é preciso que os professores sejam os sujeitos que enfrentam esse sistema, a partir de suas práticas pedagógicas como referência para construir e ressignificar os conhecimentos teóricos com os conhecimentos culturais dos educandos.

\section{REFERÊNCIAS}

ARAÚJO, Wagner Paiva. Práticas Pedagógicas no Meio Rural. (Série Amazônia: a terra e o homem). Manaus: EDUA/FAPEAM, 2004.

BARROS, José Márcio. Cultura, diversidade e os desafios do desenvolvimento humano. In: BARROS, José Márcio (Org.). Diversidade Cultural: Da proteção à promoção. Belo Horizonte: Autêntica Editora, 2008.

BRASIL. Escola Ativa. Projeto base. Brasília: Ministério da Educação, Secretaria de Educação Continuada, Alfabetização e Diversidade, 2010. (Programa Escola Ativa)

CANDAU, Vera Maria. Educação intercultural: entre afirmações e desafios. In: MOREIRA, Antonio Flavio; CANDAU, Vera Maria (Orgs.). Currículos, disciplinas escolares e culturas. Petrópolis, RJ: Vozes, 2014.

CAPELO, Maria Regina Clivati. Diversidade sociocultural na escola e a dialética da exclusão/ inclusão. In: GUSMÃO, Neusa Maria Mendes de (Org.). Diversidade, cultura e educação: olhares cruzados. São Paulo: Biruta, 2003.

CRISTO-LEITE, Ana Claúdia Peixoto de. Currículo, saberes e identidade na Amazônia das águas. In: SOUZA, Dayana Viviany Silva de; VASCONCELOS, Maria Eliane de Oliveira; HAGE, Salomão Antônio Mufarreg. Povos ribeirinhos da Amazônia: educação e pesquisa em diálogo. Curitiba: CRV, 2017.

FREIRE, Paulo. Educação como prática de liberdade. 27. ed. Rio de Janeiro: Paz e Terra, 2003.

LIRA, Talita de Melo; CHAVES, Maria do Perpétuo Socorro Rodrigues. Comunidades ribeirinhas na Amazônia: organização sociocultural e política. INTERAÇÕES, Campo Grande, MS, v. 17, n. 1, p. 66-76, jan./mar. 2016. Disponível em http://www.scielo.br/scielo.php?pid=S1518-

70122016000100066\&script=sci_abstract\&tlng=pt. Acessado em agosto de 2018.

LUCIANO, Gersem. Diversidade cultural, Educação e a questão indígena. In: BARROS, José Márcio (Org.). Diversidade Cultural: Da proteção à promoção. Belo Horizonte: Autêntica Editora, 2008.

MACEDO, Cesária Alice. Programa Cultural para o Desenvolvimento do Brasil. In: BARROS, José Márcio (Org.). Diversidade Cultural: Da proteção à promoção. Belo Horizonte: Autêntica Editora, 2008.

MACEDO, Lino de. Como construir uma escola para todos? Porto Alegre: Artmed, 2005. 
MINAYO, Maria Cecília de Souza (Org.). Pesquisa social: teoria, método e criatividade. Petrópolis, RJ: Vozes, 1994.

NUNES, Georgina Helena Lima. Educação Quilombola. In: Ministério da Educação. Secretaria da Educação Continuada, Alfabetização e Diversidade. Orientações e Ações para a Educação das Relações Étnico-Raciais. Brasília: SECAD, 2006.

PILETTI, Nelson. Psicologia Educacional. 2. ed. São Paulo: Ática, 1985.

TRIVIÑOS, Augusto Nibaldo Silva, 1928. Introdução à pesquisa em ciências sociais: a pesquisa qualitativa em educação. São Paulo:Atlas, 1987.

Recebido em: 06/07/2019

Aprovado em: 29/07/2019 